\title{
Effect of drops containing Lactobacillus reuteri (DSM 17938 and ATCC PTA 5289) on plaque acidogenicity and other caries- related variables in orthodontic patients
}

Sahal Alforaidi ${ }^{1,2^{*}}$, Andrea Bresin ${ }^{3,4}$, Naif Almosa ${ }^{5}$, Anna Lehrkinder $^{1}$ and Peter Lingström ${ }^{1}$

\begin{abstract}
Background: The purpose of the study was to investigate the effect of probiotics on biofilm acidogenicity and on the number of salivary Streptococcus mutans and lactobacilli in orthodontic patients.

Methods: This RCT was conducted on 28 young adults who were undergoing orthodontic treatment. The shortterm prospective clinical trial lasted for three weeks. The test group rinsed daily with drops containing two Lactobacillus reuteri strains diluted in water, while the placebo group used drops without probiotics. The subjects were enrolled eight months since the beginning of orthodontic treatment. Plaque-pH, saliva and dental biofilm samples were obtained at baseline, one week and three weeks post intervention.

Results: Twenty-seven subjects successfully completed the trial period, only one drop out in the test group. No side effects were reported. A statistically significant increase in plaque $\mathrm{pH}$ at three weeks post-intervention was found for the test group $(p<0.05)$, while insignificant changes in the $\mathrm{pH}$ value were found for the placebo group in comparison to baseline $(p>0.05)$. In addition, the $A_{U} C_{7.0}$ showed a significant difference at three weeks between the test and placebo $(p=0.00002)$. The three-week samples of stimulated whole saliva showed a statistically insignificant difference in the number of $S$. mutans and lactobacilli between the two groups $(p>0.05)$. The $q P C R$ analysis showed the ability of the two strains to get colonized in the dental biofilm without a significant effect on the microbial counts.

Conclusion/clinical implications: A mixture of Lactobacillus reuteri has the ability to reduce the $\mathrm{pH}$ fall at the three-week follow-up. However, the short-term use of probiotics does not appear to have an effect on the number of salivary Streptococcus mutans and lactobacilli in saliva and on the dental biofilm.
\end{abstract}

Trial registration: Clinicaltrial.gov (Identifier: NCT04593017/ (19/10/2020)).

Keywords: Dental biofilm, Dental plaque Lactobacillus reuteri (L. reuteri), Plaque pH, Probiotics Saliva, Streptococcus mutans (S.mutans), Quantitative polymerase chain reaction (qPCR)

\footnotetext{
* Correspondence: dr.sahal.sweden@hotmail.com

'Department of Cariology, Institute of Odontology, The Sahlgrenska

Academy, University of Gothenburg, Gothenburg, Sweden

${ }^{2}$ Department of Pediatric Dentistry and Orthodontics, College of Dentistry,

Taibah University, Medina, Saudi Arabia

Full list of author information is available at the end of the article
}

(c) The Author(s). 2021 Open Access This article is licensed under a Creative Commons Attribution 4.0 International License, which permits use, sharing, adaptation, distribution and reproduction in any medium or format, as long as you give appropriate credit to the original author(s) and the source, provide a link to the Creative Commons licence, and indicate if changes were made. The images or other third party material in this article are included in the article's Creative Commons licence, unless indicated otherwise in a credit line to the material. If material is not included in the article's Creative Commons licence and your intended use is not permitted by statutory regulation or exceeds the permitted use, you will need to obtain permission directly from the copyright holder. To view a copy of this licence, visit http://creativecommons.org/licenses/by/4.0/. The Creative Commons Public Domain Dedication waiver (http://creativecommons.org/publicdomain/zero/1.0/) applies to the data made available in this article, unless otherwise stated in a credit line to the data. 


\section{Background}

Dental caries is one of the chronic diseases most commonly affecting oral health. The disease occurs as a result of the interaction between cariogenic bacteria (such as mutans streptococci and lactobacilli), a diet rich in fermentable carbohydrates and a susceptible host, including the saliva secretion rate and buffering capacity over a period of time [1]. Subsequently, the acid production resulting from carbohydrate metabolism by cariogenic bacteria will reduce the environmental $\mathrm{pH}$, which will lead to mineral loss [2]. In addition, a number of factors, such as socioeconomic status, biological factors and genetics, may also be regarded as important factors for dental caries [3, 4]. Different strategies, such as fluoride application, dietary modification and oral hygiene, have been suggested to diminish or reverse enamel demineralisation. Lately, the intake of live bacteria of human origin has been added as a preventive strategy. Moreover, antibiotics and antimicrobial treatment with chlorhexidine have attracted attention over the last few years. However, the use of wide-spectrum antibiotics and antimicrobial treatment may reduce the caries risk but will never eliminate it, which means that they must be taken at regular intervals over the long term [5]. The use of bacteriotherapy is a fairly new concept in preventive dentistry, despite its long-time use in the prevention and treatment of gastrointestinal diseases. Lactobacillus reuteri is one of the microorganisms that has been extensively reviewed and showed their ability to produce antimicrobial substances [6]. Although the full mechanisms of probiotic action are still poorly understood, it is believed that these microorganisms have the ability to compete with pathogenic bacteria known to be hazardous to the health, as well as local and systemic immunomodulation [7, 8]. Previous short-term studies have revealed a positive effect by different probiotic microorganisms, resulting in a reduction in the number of mutans streptococci $[9,10]$. Other clinical trials have tested the effect of probiotics with caries as the endpoint $[11,12]$. Several vehicles, such as tablets, lozenges, chewing gum, cheese, yogurt and different bacterial strains, have been used. However, the best vehicle for probiotic delivery for different patient groups has yet to be identified. Orthodontic patients undergoing treatment with fixed appliances may require additional preventive strategies that might help to reduce the caries risk throughout the treatment progress and raise the standard care of the patients. Previous researchers have reported a significant increase in the number of cariogenic bacteria in the dental biofilm during orthodontic treatment following the placement of the appliances [13]. To date, studies investigating the probiotic effect on orthodontic patients at the level of the bacterial change are limited and not explored in any depth with conflicting results.
In addition, drops as a vehicle for probiotic administration in patients wearing orthodontic appliances have never been used before. Our primary aim was therefore to investigate the short-term effect of probiotic drops on plaque acidogenicity among orthodontic patients. The secondary outcome was the effect of probiotics on the level of Streptococcus mutans and lactobacilli in the saliva. The null hypothesis is that the effect of probiotics would not differ from that in a placebo-treated control group.

\section{Materials and methods \\ Participants}

The sample population consisted of 28 subjects, fourteen males and fourteen females, with a mean age of $17.3 \pm$ 1.1 years, who were undergoing orthodontic treatment at the Specialist Clinic of Orthodontics, Public Dental Service, Gothenburg, Region Västra Götaland, Sweden. The sample size calculation was based on a significance level of 5 and $80 \%$ power in order to detect the difference in plaque acidogenicity with an estimated difference in $\mathrm{pH}$ fall of $0.4, \mathrm{SD} 0.35$. The power calculation revealed that, twelve subjects are needed in each arm, additional two subjects were added in each group accounting for the drop out. The inclusion criteria were subjects with a large number of Streptococcus mutans ( $>10^{4} \mathrm{CFU} / \mathrm{ml}$ of saliva), undergoing bimaxillary fixed orthodontic treatment, over a period of time lasting eight months since the onset of bonding, medically healthy, no medications, free of any systemic diseases and with the ability to understand the nature of the study. The exclusion criteria were patients with cleft lip and palate syndrome, handicapped patients, individuals with systemic diseases or conditions that could interfere with the study and a history of probiotics/anti-inflammatory drugs/antimicrobial substances taken during the last four weeks prior to the baseline examination. A saliva screening test was carried out to identify high caries risk subjects based on the number of Streptococcus mutans prior to study. Of 60 screened subjects, 28 were selected for the present study, ten subjects did not meet the inclusion criteria and twenty declined to participate. The subjects were stratified into the test and placebo groups based on gender and the level of Streptococcus mutans (Fig. 1). All the subjects had good oral health with no open or untreated carious lesions and a mean DMFT of $0.4 \pm 0.8$ and they claimed that they brushed their teeth twice a day.

The subjects were instructed to avoid other probioticcontaining products such as xylitol chewing gums and antibiotics during the study. The study protocol was in accordance with the Helsinki Declaration of Human Rights and was approved by the Ethics Committee at the University of Gothenburg (788-18). The subjects received both oral and written information about the study 


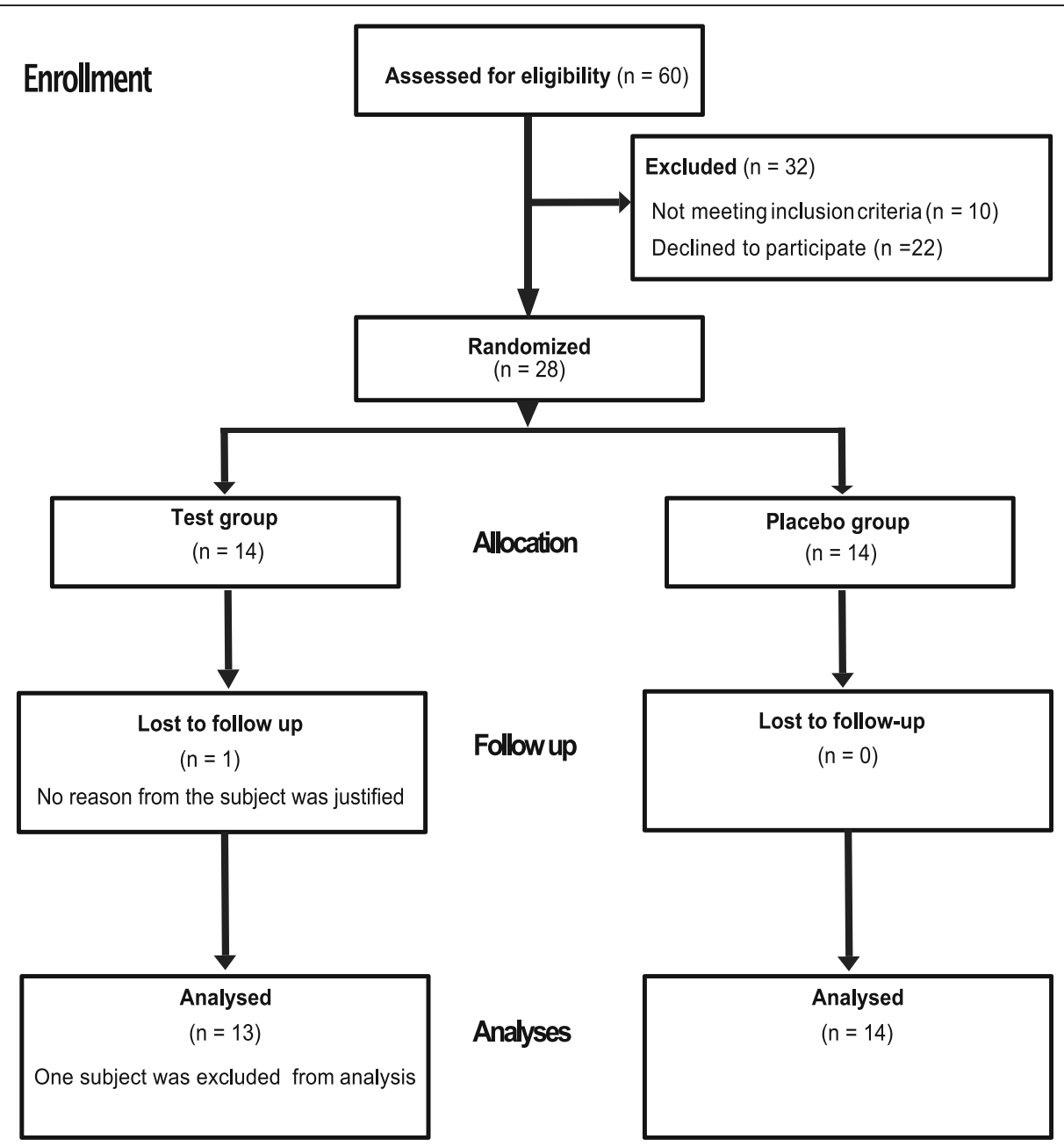

Fig. 1 Flow chart of randomization and attrition of participants throughout the study period

and gave their informed consent prior to the start of the study.

\section{Study design}

The study has been registered at Clinicaltrial.gov with ID number NCT04593017/ (19/10/2020). The study was designed as a double-blind study, in which neither the investigator nor the participants were aware of the groups they were enrolled in. It was a placebocontrolled, randomised clinical trial with two parallel arms and comprised a three-week intervention following the CONSORT guidelines. The subjects were randomly assigned using an Excel program after stratification based on gender and the level of S. mutans performed by an independent member (A.L.) who worked as a microbiologist. Allocation was made to one of the two groups: A) test, mouth rinse using drops containing two strains of the probiotic bacterium Lactobacillus reuteri, and B) placebo, mouth rinse using identical drops without any active probiotic bacteria. The rinses were administered in the morning after breakfast and toothbrushing and in the evening before going to bed. Rinsing was at each time point carried out for $60 \mathrm{~s}$ after which the solution was spat out. No eating or drinking were allowed during the following two hours. The subjects were told to brush their teeth twice a day. For standardisation purposes, the same toothpaste (Folktandkräm, Proxident $A B$, Sweden) was distributed to all the participants.

\section{Study drops}

The probiotic drops, BioGaia Prodentis drops (BioGaia AB, Stockholm, Sweden), contained freeze-dried L. reuteri DSM $17938\left(>1 \times 10^{8} \mathrm{CFU} / 5\right.$ drops) and L. reuteri ATCC PTA $5289\left(>1 \times 10^{8}\right.$ CFU/5 drops) suspended in an oil [14]. The daily intake was 0.15 to $0.20 \mathrm{~g}$ ( 5 drops). The probiotic solution was prepared fresh by the test subject prior to each rinsing session by mixing five drops of a probiotic oil (L. reuteri DSM 17938 and L. reuteri ATCC PTA 5289) with $5 \mathrm{ml}$ of distilled water according 
to the manufacturer instructions. Tubes were filled with $5 \mathrm{ml}$ of distilled water and distributed to all subjects at each time point. During the study, the participants were instructed to keep the water and drops in a refrigerator when not in use. Compliance regarding the use of probiotics was checked using a special mobile app, MyMedschedule ${ }^{R}$ Plus, which reflects the mean percentage of mouth rinses with probiotics during the study period through a reminder which was given at a specific time every day.

\section{Clinical variables}

The subjects came to the Department of Cariology, Institute of Odontology, for the collection of oral samples before the start of probiotic administration, one week post intervention and after three weeks' administration of probiotic/placebo. The participants were asked to refrain from proximal cleaning for $48 \mathrm{~h}$ and toothbrushing for $24 \mathrm{~h}$ prior to each sampling session. On each visit, plaque $\mathrm{pH}$, dental biofilm and saliva were assessed.

\section{Biofilm acidogenicity}

Plaque $\mathrm{pH}$ was assessed using the strip method for all subjects and at all time points based on the technique described by Carlén et al [15], except for one subject in the test group in which $\mathrm{pH}$ was taken only at baseline as a result of drop out. A pH indicator strip (Spezialindikator, Merck, Darmstadt, Germany) was used to measure the $\mathrm{pH}$ value $(4.0-7.0)$. Each strip was cut into three pieces and inserted in the interproximal area (under the contact point of the teeth) of the lateral incisors/canines in the left and right upper regions, before $(0 \mathrm{~min})$ and 2 , 5, 10, 20 and $30 \mathrm{~min}$ after a one-minute mouth rinse with $10 \mathrm{~mL}$ of a $10 \%$ sucrose solution. In order to assess the $\mathrm{pH}$ values, comparisons were made between the colour appearing on the inserted strip and the index chart provided by the manufacturer. The two examiners (S.A. \& A.A.) performing the $\mathrm{pH}$ measurements were assessed for inter-examiner reliability where the Kappa statistics revealed 0.93 .

\section{Dental plaque and saliva sampling}

Deep inter-proximal plaque samples were collected between the upper lateral incisors and canines on both sites using a sterile toothpick and then transferred immediately into microtubes with TA buffer for the detection and quantification of the probiotic strains under qPCR analysis.

Whole stimulated saliva was collected as previously described [16], where $5 \mathrm{ml}$ of stimulated whole saliva was collected by getting the subjects to chew on $1 \mathrm{~g}$ of paraffin wax for five minutes and collected directly in a graded test tube, after which the secretion rate was calculated in $\mathrm{ml} / \mathrm{min}$. One $\mathrm{ml}$ was transferred to VMGII medium for microbiological analysis of the level of $S$. mutans and lactobacilli and $1 \mathrm{ml}$ was also utilised for buffer capacity [17].

\section{Microbiological analysis of the saliva sample}

All the samples were analysed at the Department of Cariology, the Institute of Odontology, Sahlgrenska Academy, University of Gothenburg, Sweden. After serial dilutions, counts of the salivary number of Streptococcus mutans and lactobacilli were evaluated using Mitis Salivarius agar (Sigma-Aldrich, NutriSelect ${ }^{\circ}$ Plus, Germany) supplemented with $10 \%$ sucrose and bacitracin $(0.2 \mathrm{U} /$ $\mathrm{ml}$ ) and Rogosa agar under anaerobic conditions at specific temperatures and incubation periods, as previously mentioned [14]. The number of colony-forming units were enumerated on the agar and for S. Mutans identified based on specific characteristic colony morphology. Rogosa agar is selective for all lactobacilli.

\section{Quantitative polymerase chain reaction (qPCR)}

Identification and quantification were performed as previously described [14]. Briefly, prior to qPCR analysis, tubes with plaque samples were placed in a thermoshaker (TS-100C, Biosan SIA, Latvia) for $10 \mathrm{~min}$ at $95^{\circ} \mathrm{C}$ and $1000 \mathrm{rpm}$ to release genomic DNA. The qPCR relative quantification analysis was performed on an MIC analyser (Bio Molecular Systems, Upper Coomera, Australia). A conserved region (BAC16S) in the ribosomal gene, present in all bacteria, was used as the reference gene and both strain-specific and species-specific primers for L. reuteri, S. mutans, lactobacilli and streptococci were used as the gene of interest in the relative quantification analysis.

In total, the reaction mixture of $20 \mu \mathrm{l}$ contained $1 \mathrm{x}$ qPCRBIO SyGreen mix (PCR BioSystems, London, UK), $400 \mathrm{nM}$ of each forward and reverse primer (Sigma-Aldrich Co., LLC) and $2.5 \mu \mathrm{l}(<1 \mu \mathrm{g}$ genomic) DNA template. All amplifications were carried out as duplicates in MIC tubes and caps (BioMolecular Systems, Upper Coomera, Australia). The relative expression software tool (REST) on the MIC analyser (Bio Molecular Systems, Australia) was used to perform the analysis. The details of each assay and primer sequence are presented in Table 1.

\section{Statistical analysis}

The mean $\mathrm{pH}$ of the $\mathrm{pH}$ readings for each individual site was calculated. The mean for the two sites at each of the different time points was calculated, as well as the minimum $\mathrm{pH}$ and maximum $\mathrm{pH}$ fall. The area under the curve $\left(\mathrm{AUC}_{7.0}\right)$ was calculated using Prism software. The mean \pm SD and $95 \%$ confidence interval for the salivary S. mutans and lactobacilli concentrations were calculated for each group. 
Table 1 Primer sequence and QPCR conditions used for relative quantification analysis

\begin{tabular}{|c|c|c|}
\hline & Primer sequence $5^{\prime}-3^{\prime}$ & qPCR program \\
\hline Streptococcus mutans & Forward: CTACACTITCGGGTGGCTTG & $95^{\circ} \mathrm{C} 2 \mathrm{~min}$ \\
\hline Choi et al., 2009 [18] & Reverse: GAAGCTTITCACCATTAGAAGCTG & $\begin{array}{l}40 \times 95^{\circ} \mathrm{C} 10 \mathrm{~s}, 61^{\circ} \mathrm{C} 20 \mathrm{~s}, \\
\text { Plate read }\end{array}$ \\
\hline $\begin{array}{l}\text { Total bacteria } \\
\text { (reference gene) }\end{array}$ & Forward: TGGAGCATGTGGTITAATTCGA & $94^{\circ} \mathrm{C} 4 \mathrm{~min}$ \\
\hline Choi et al., 2009 [18] & Reverse: TGCGGGACTTAACCCAACA & $\begin{array}{l}40 \times 94^{\circ} \mathrm{C} 20 \mathrm{~s}, 62^{\circ} \mathrm{C} 20 \mathrm{~s}, \\
\text { Plate read }\end{array}$ \\
\hline Total lactobacillus & Forward: TGGAAACAGRTGCTAATACCG & $98^{\circ} \mathrm{C} 2 \mathrm{~min}$ \\
\hline Roy et al., 2004 [19] & Reverse: GTCCATTGTGGAAGATTCCC & $\begin{array}{l}40 \times 98^{\circ} \mathrm{C} 10 \mathrm{~s}, 62^{\circ} \mathrm{C} 15 \mathrm{~s}, \\
\text { Plate read }\end{array}$ \\
\hline $\begin{array}{l}\text { Lactobacillus reuteri } \\
\text { DSM } 17938\end{array}$ & Forward: TTAAGGATGCAAACCCGAAC & $98^{\circ} \mathrm{C} 2 \mathrm{~min}$ \\
\hline $\begin{array}{l}\text { Vestman et al., } 2013 \\
\text { [20] }\end{array}$ & reverse: CCTTGTCACCTGGAACCACT & $\begin{array}{l}40 \times 98^{\circ} \mathrm{C} 5 \mathrm{~s} \text { and } 60^{\circ} \mathrm{C} 15 \mathrm{~s} \text {, } \\
\text { Plate read }\end{array}$ \\
\hline $\begin{array}{l}\text { Lactobacillus reuteri } \\
\text { PTA } 5289\end{array}$ & Forward: GACAGTGGCTAAACGCCTC & $98^{\circ} \mathrm{C} 2 \mathrm{~min}$ \\
\hline $\begin{array}{l}\text { Vestman et al., } 2013 \\
\text { [20] }\end{array}$ & Reverse: AATTCCACTTGCCATCTTCG & $\begin{array}{l}40 \times 98^{\circ} \mathrm{C} 5 \mathrm{~s} \text { and } 60^{\circ} \mathrm{C} 15 \mathrm{~s} \text {, } \\
\text { Plate read }\end{array}$ \\
\hline Total Streptococci & Forward: YGTGCAATTITTGGATAAT & $95^{\circ} \mathrm{C} 3 \mathrm{~min}$ \\
\hline $\begin{array}{l}\text { Täpp et al., } 2003 \\
{[21]}\end{array}$ & Reverse: TTCTATAAGCCATGTITTGT & $\begin{array}{l}40 \times 94^{\circ} \mathrm{C} 20 \mathrm{~s}, 52^{\circ} \mathrm{C} 30 \mathrm{~s}, \\
\text { Plate Read }\end{array}$ \\
\hline
\end{tabular}

The data analysis was processed and analysed with GraphPad Prism software (version 8.2.0 (272)). Two-way analysis of variance (ANOVA) followed by Tukey's multiple comparisons test was used for the changes in the $\mathrm{pH}$ value within the test and placebo groups. Comparisons of changes in the plaque $\mathrm{pH}$ between the two groups were made using Sidak's multiple comparisons test. Detailed information regarding the $\mathrm{pH}$ readings was reported using paired t-test. Salivary cariogenic bacteria between the test and control groups were assessed using a two-way ANOVA test. Changes in the buffer capacity between the two groups was tested using paired t-test. The relative quantification of investigated probiotic bacteria species in plaque was carried out using qPCR gene expression analysis (Bio Molecular Systems, Australia), a statistical analysis was carried out using one-way ANOVA followed by Tukey's comparison test. A difference with a value of $p<0.05$ was considered to be statistically significant.

\section{Results}

Twenty-seven subjects successfully completed the trial period, only one drop-out subject in the test group was recorded after baseline, the compliance was high (99\%) based on the use of the MyMedschedule ${ }^{R}$ plus app, the percentage expressed the mean of the overall use by all participants during the trial period. No negative sideeffects were reported in either group.

At baseline, the plaque $\mathrm{pH}$ and the number of salivary Streptococcus mutans and lactobacilli did not show any statistically significant difference for the observed variables between the test and placebo groups $(p=0.1)$ (Tables 2 and 3).

Figures 2 and 3 show the plaque-pH curves obtained at baseline and the one-week and three-week follow-up for the test and placebo groups. For the test group, a statistically significant increase in plaque $\mathrm{pH}$ between baseline and the one-week follow-up and between baseline and the end of the intervention was found $(p<0.05)$. However, for the placebo group, there was no statistical difference at any of the time points.

Table 3 shows detailed information regarding the $\mathrm{pH}$ measurements. The results revealed a statistically insignificant difference between the test and placebo group based on the baseline $\mathrm{pH}$ value at all three time points $(p>0.05)$, but only the maximum $\mathrm{pH}$ fall was found to be significant at baseline $(p<0.05)$. Minor insignificant changes regarding the mean minimum $\mathrm{pH}$ value at baseline and at one week post intervention were seen, but, three weeks post intervention, the value started to be significant between two groups $(p<0.05)$. Furthermore, the values for the $\mathrm{AUC}_{7.0}$ between the test and placebo group were significant at baseline and one week post intervention. It is noteworthy that the largest difference seen when comparing the two groups was at the end of the intervention period $(p=0.00002)$.

Changes in the level of S. mutans and lactobacilli after probiotic use are presented in Fig. 4. No statistical difference was found for the salivary level of $S$. mutans and the level of lactobacilli between the test and placebo 
Table 2 Comparison of the level of S. mutans and lactobacilli between the two groups at baseline, one week post intervention and three weeks post intervention. The data are expressed in terms of the mean, 95\% confidence interval and level of significance at $p<0.05$

\begin{tabular}{|c|c|c|c|}
\hline & Mean difference & $95 \% \mathrm{Cl}$ & $P$ value \\
\hline \multicolumn{4}{|l|}{ Baseline (t0) } \\
\hline S. mutans test vs S. mutans placebo & 0.066 & -0.906 to 1.038 & $>0.05$ \\
\hline Lactobacilli test vs Lactobacilli placebo & -0.043 & -1.064 to 0.978 & $>0.05$ \\
\hline \multicolumn{4}{|l|}{ One week (t1) } \\
\hline S. mutans test vs S. mutans placebo & -0.098 & -1.089 to 0.893 & $>0.05$ \\
\hline Lactobacilli test vs Lactobacilli placebo & 0.221 & -0.814 to 1.256 & $>0.05$ \\
\hline \multicolumn{4}{|l|}{ Three week (t2) } \\
\hline S. mutans test vs S. mutans placebo & -0.081 & -1.116 to 0.954 & $>0.05$ \\
\hline Lactobacilli test vs Lactobacilli placebo & 0.204 & $-0,790$ to 1199 & $>0.05$ \\
\hline
\end{tabular}

groups during the intervention period based on the cultural analysis $(p>0.05)$. It is worth noting that the level of salivary $S$. mutans and lactobacilli was more stable in the test group in comparison with the placebo group in which an increase was noted during the trial period. The overall salivary secretion rates for the individuals in the test and placebo groups were within normal with a mean for the three test visits of $1.78 \pm 0.88$ for the test group, and a mean of $1.50 \pm 0.51$ for the placebo group (ns). The results showed a numerical increase in buffer capacity for the test group $(5.5 \pm 1.1$ for baseline, $5.9 \pm 1.2$ for 1 week and $6.0 \pm 1.2$ for 3 weeks; (ns), while no such trend was found for the placebo group $(5.6 \pm 1.2$ for baseline, $5.7 \pm 1.2$ for 1 week and $5.6 \pm 0.9$ for 3 weeks).

The qPCR analysis of the dental biofilm showed that the two Lactobacillus reuteri strains, DSM 17938 and PTA 5289, were both detected for the test group at one week and at the three-week follow-up, with an increased value compared with baseline $(p<0.05)$, but both strains showed no effect on the total lactobacilli or total streptococci in relation to the total bacterial counts in the test and the placebo group (Table 4).

\section{Discussion}

The effect of two strains of Lactobacillus reuteri administered twice daily on the plaque acidogenicity, on the level of salivary cariogenic bacteria and on the dental biofilm in a group of patients wearing orthodontic appliances in the short term was investigated. The novel aspect of this study is that, to date, the effect of probiotics on orthodontic patients has not been widely studied. In addition, $\mathrm{pH}$ and $\mathrm{qPCR}$ analyses are rarely used as methods when evaluating the outcome after probiotic administration.

It is worth noting that drops as a vehicle for probiotic administration have never been used on patients wearing orthodontic appliances. Hypothetically, this type of medium, when administered as a mouth rinse, may easily obtain access to the tooth surface around the wires and brackets. Other administrative modes, such as lozenges [22], yoghurt [23], probiotic curd and toothpaste [24], have previously been used by subjects undergoing orthodontic treatment.

The main outcome of this study was that probiotics in form of drops was significantly effective in reducing the plaque acidogenicity for the test group when compared to the placebo group after three weeks' intervention.

Table 3 Information about $\mathrm{pH}$ measurements regarding baseline $\mathrm{pH}$ value, maximum $\mathrm{pH}$ fall, final $\mathrm{pH}$, mean minimum $\mathrm{pH}$ value and the AUC at a critical value of $\mathrm{pH}$ 7. A comparison was made between the test and control group at the level of $p<0.05$

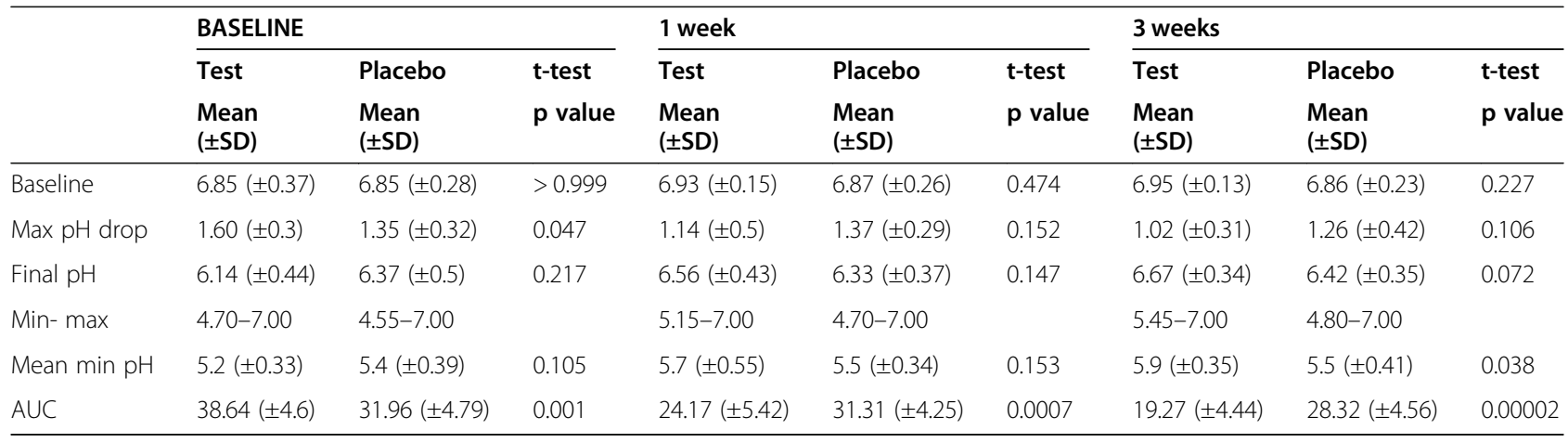




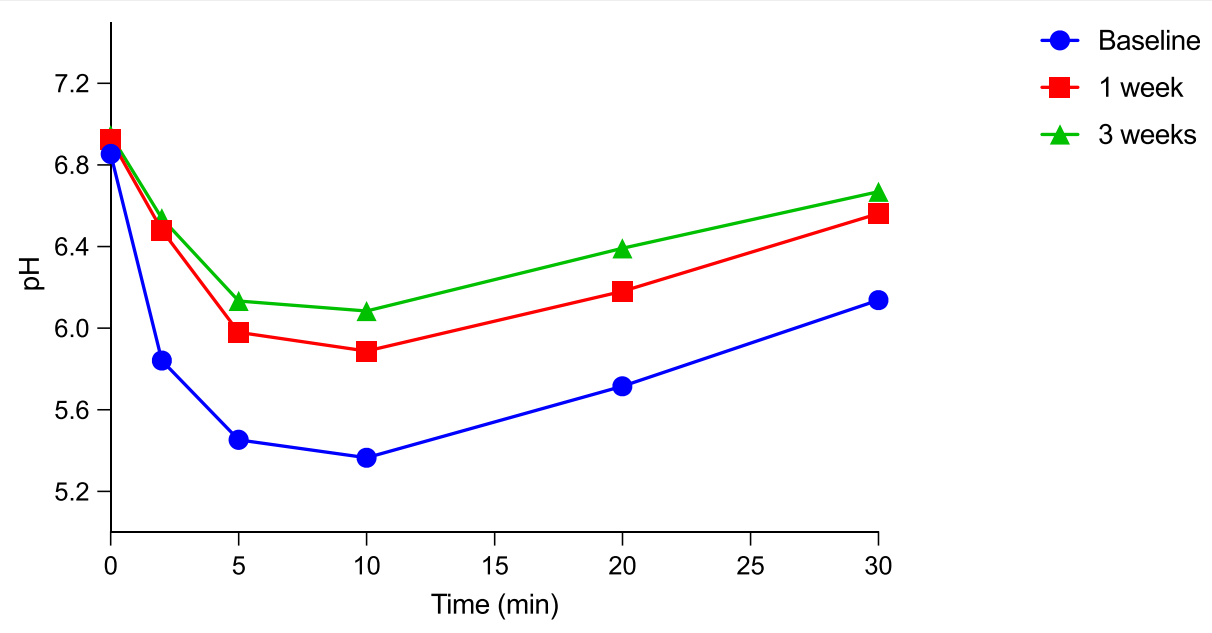

Fig. 2 The curve shows the plaque-pH curves obtained at baseline, the one-week and the three-week follow-ups for the test group

The null hypothesis could thus be rejected. Noteworthy, plaque acidogenicity was not considered as an outcome in any other clinical trials investigating the effect of probiotic on subjects wearing orthodontic appliances. Our study is in accordance with previous work in which probiotics was tested on high caries risk schoolchildren during a six week intervention period [25]. In contrast, the effect of probiotics lozenges on plaque $\mathrm{pH}$ has been investigated in young adults without orthodontic appliances. The study found no statistical significant difference between the test and placebo groups after two weeks of probiotics administration [26]. The short time period may explain these results, indicating the importance of continuous administration in order to attain the desired effect [27]. The results showed that, at baseline, both groups were matched. However, there was a significant difference in the maximum $\mathrm{pH}$ fall and in the area under the curve, which might be related to the inter- individual variations. For both parameters, the same pattern, in which the probiotic had more effect in the test group at the one-week and three-week follow-up, can be seen. The dental biofilm is regarded as a key factor in the caries process [28]. For this reason, a decrease in the plaque $\mathrm{pH}$ will result in the activation of the acidogenic bacteria, which may in turn result in significant tooth demineralisation [29]. Different tools, such as strips and electrodes, can be used for $\mathrm{pH}$ determination. In this case, the strip method was used as an equally effective tool reflecting plaque acidogenicity [15].

Most orthodontic patients suffer from retentive sites as a result of teeth irregularities and the presence of the orthodontic appliances which may contribute to the retention of $S$. mutans during the fixed orthodontic treatment [30]. This may in turn increase the risk of caries development and, in particular, the development of white spot lesions around the brackets [31]. In the present study, we

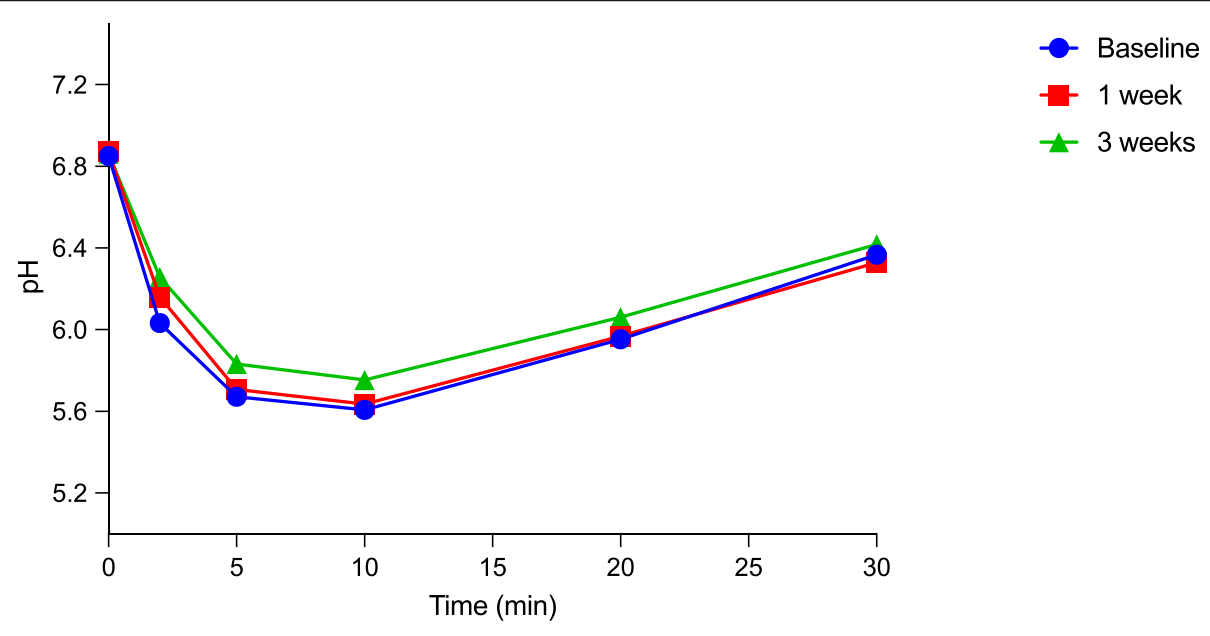

Fig. 3 The curve shows the plaque-pH curves obtained at baseline, the one-week and the three-week follow-ups for the placebo group 


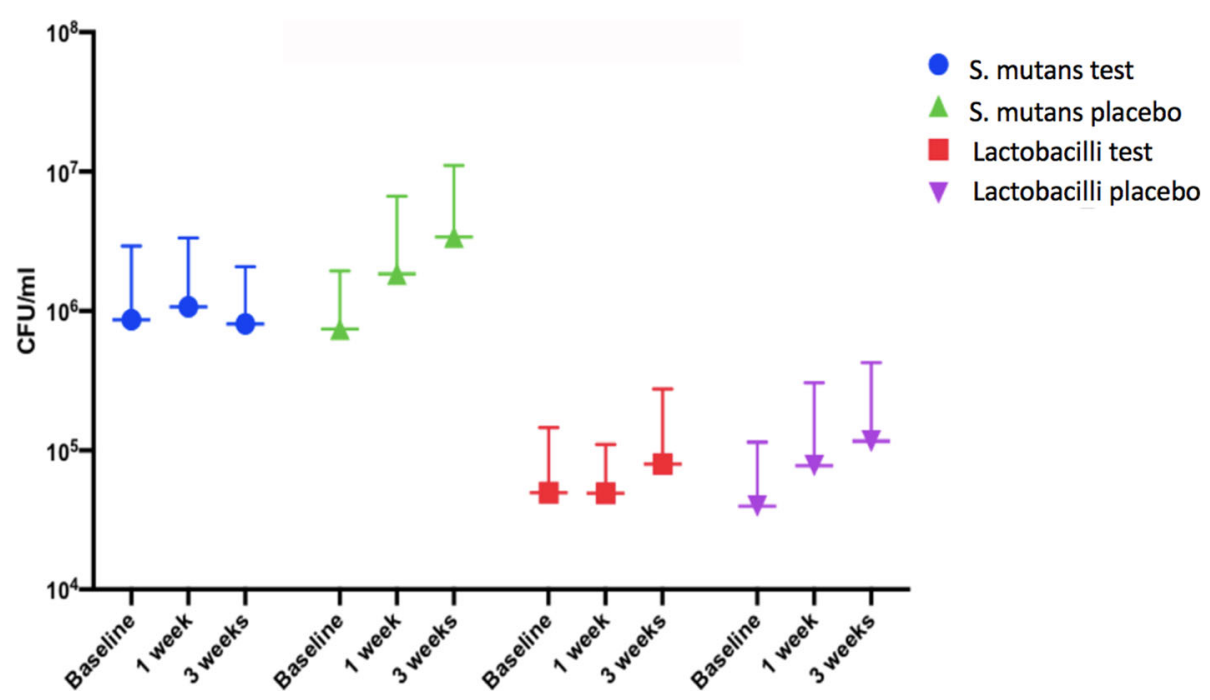

Fig. 4 Salivary prevalence of S. mutans and total lactobacilli in the test and placebo groups at baseline, one week and three weeks post intervention. $(p<0.05)$

found that drops containing two strains of probiotic $L$. reuteri did not help in reducing the number of $S$. mutans or the total number of lactobacilli in saliva after shortterm use. However, contrary to the typical oral environment in orthodontic patients, the number of $S$. mutans and the total number of lactobacilli were fairly stable in the test group in comparison to the placebo group, in which a pronounced increase was noted. The present work is in agreement with previous work, in which the long-term use of probiotics in the form of lozenges administered once a day has no effect on the level of salivary S. mutans [22], whereas a significant reduction in the salivary mutans streptococci has been found in a group of orthodontic patients using probiotic yogurt containing Bifidobacterium animalis subsp. based on a chairside kit [10]. In a previous study using drops containing probiotics, our research team found a significant reduction in the number of $S$. mutans after four weeks of administration, where the oral environment is different from that in subjects wearing fixed appliances [14]. An interesting finding was that the buffer capacity increased during the three weeks for the test group in comparison to the placebo group. The exact explanation for the observed positive changes of biofilm acidogenicity cannot be explained by current data. Complex probiotic mechanisms suggested behind this action are normalisation of the oral microbiota, metabolic effects and modulation of the immune response [32], It is believed that the two first strategies play a central role in modulating $\mathrm{pH}$.

The participants in the present study were enrolled eight months into their orthodontic treatment. The level of $S$. mutans and lactobacilli in the saliva and dental plaque has been shown to reach the highest level at this time point, which is regarded as an important factor for the risk of caries [33].

Table 4 Relative quantification of investigated bacteria species in plaque based on gene expression ratio. $(p<0.05)$

\begin{tabular}{|c|c|c|c|}
\hline \multicolumn{2}{|l|}{$p$-value in relation to baseline } & $\begin{array}{l}\text { Week } 1 \\
\text { Whole mouth }\end{array}$ & $\begin{array}{l}\text { Week } 3 \\
\text { Whole mouth }\end{array}$ \\
\hline \multirow{3}{*}{ Lactobacillus reuteri DSM/total lactobacilli } & & & \\
\hline & Test & 0.0015 (up) & 0.0065 (up) \\
\hline & Placebo & Too few samples & Too few samples \\
\hline \multirow[t]{2}{*}{ Lactobacillus reuteri PTA/total lactobacilli } & Test & 0.028 (up) & 0.009 (up) \\
\hline & Placebo & Too few samples & Too few samples \\
\hline \multirow[t]{2}{*}{ Total lactobacilli/total bacteria count } & Test & 0.762 (no difference) & 0.84 (no difference) \\
\hline & Placebo & 0.929 (no difference) & 0.662 (no difference) \\
\hline \multirow[t]{2}{*}{ Streptococcus mutans/total streptococci } & Test & 0.8305 (no difference) & 0.986 (no difference) \\
\hline & Placebo & 0.644 (no difference) & 0.549 (no difference) \\
\hline \multirow[t]{2}{*}{ Total streptococci/total bacteria count } & Test & 0.356 (no difference) & 0.249 (no difference) \\
\hline & Placebo & 0.678 (no difference) & 0.947 (no difference) \\
\hline
\end{tabular}


The results should be interpreted with caution for the following reasons: the short intervention period, the appropriate dose per day and the most optimal vehicle for probiotic administration.

Quantitative PCR using strain-specific and speciesspecific primer is a well-known method not only for detection but also as an accurate and reliable tool for bacterial quantification [34]. Plaque samples were collected between the upper lateral incisors and canines, as this area is the one most affected by caries in orthodontic patients [35-37]. In the present study, qPCR analysis indicated the ability of the probiotic to colonise the dental biofilm in the test group during the trial period, while no additional benefits at the level of the microbial effect could be seen. Few studies have investigated the effect of probiotics on microbial changes based on the PCR analysis. A study in which the effect of the probiotics in the form of systemic curd and toothpaste was tested on the dental biofilm found a significant reduction in $S$. mutans after 30 days in a group of orthodontic patients [24], while another study in the same group of patients found a similar effect when comparing the probiotic yogurt and the control yogurt on the reduction in mutans streptococci in both saliva and dental-plaque samples after short-term use [23]. There are different reasons for the conflicting results, such as the study design, the length of the trial period, the methods of microbial analysis, administration modes, age group, stage of orthodontic treatment and active probiotic strain. Additionally, although it is well known a large number of microorganism are involved in the caries process, only a limited number of highly relevant cariogenic microorganism were evaluated in the present study.

The results of our study call for long-term studies in this high-risk group to investigate whether probiotics can be regarded as an additional regimen in terms of caries prevention and to compare other strategies such as fluoride therapy and antibiotics in terms of sideeffects and cost effectiveness.

\section{Conclusion}

Probiotics appear to reduce the drop in plaque $\mathrm{pH}$ after a short period of use. However, it is unclear whether the effect of probiotics on $\mathrm{pH}$ will be maintained for a prolonged period of several months of orthodontic treatment with fixed appliances. If so, it may have a preventive effect on the development of carious lesions during orthodontic treatment. Further longitudinal studies of the prolonged use of probiotics in orthodontic patients and the development of carious lesions are needed to elucidate those hypotheses.

\section{Abbreviations}

ANOVA: Analysis of Variance; $\mathrm{AUC}_{7.0}$ : Area under the curve below pH 7.0; CFU: Colony-forming units; DNA: Deoxyribonucleic Acid; DMFT: The sum of the number of Decayed, Missing and Filled Teeth in the permanent dentition; L. reuteri: Lactobacillus reuteri; Max: Maximum; Min: Minimum; ns: Non-significant; $\mathrm{pH}$ : Potential of hydrogen or power of hydrogen; qPCR: Quantitative polymerase chain reaction; RCT: Randomized Clinical trial; S. mutans : Streptococcus mutans; SD: Standard deviation; TA buffer: Tris Acetate Buffer; VMGII medium: Viable medium by Gothenburg

\section{Acknowledgements \\ The authors thank BioGaia AB, Stockholm, Sweden, for providing the probiotic drops and for help performing the study. Also, the author would like to thank the Specialist Clinic of Orthodontics, Public Dental Service, Gothenburg, Region Västra Götaland, Sweden for giving us the opportunity and the accessibility to perform the study. Also, the author would like to thank Ali Alshabeeb (A.A.) for helping out with data collection concerning plaque $\mathrm{pH}$. This study was conducted as part of a project supported by a scholarship from the Ministry of Higher Education, Saudi Arabia.}

\section{Authors' contributions}

S.A., A.B., N.A., and P.L. designed and planned the study. S.A. collected the data and prepared the samples. S.A. performed the measurements. S.A. performed the statistical analyses and wrote the draft of the manuscript. A.L. conducted the microbiological and molecular analysis. All the authors commented on and revised the manuscript. The author(s) read and approved the final manuscript.

\section{Funding}

This study was conducted as part of a project supported by a scholarship from the Ministry of Higher Education, Taibah University, Saudi Arabia. Probiotic drops were obtained from the manufacturer, BioGaia AB (Stockholm, Sweden). The supplier played no role in the study design or implementation, data analysis, decision to publish, or manuscript preparation. The authors declare no conflicts of interest. Open Access funding provided by University of Gothenburg.

\section{Availability of data and materials}

All the primer sequences were referenced to a published works by Vestman et al., https://pubmed.ncbi.nlm.nih.gov/23486236/, https://pubmed.ncbi.nlm. nih.gov/25946126/. Probiotics bacteria L. reuteri was obtained from the manufacturer (Biogaia, Stockholm) as commercial strains. There is no data to deposit in a database. No sequencing has been performed.

\section{Declarations}

\section{Ethics approval and consent to participate}

The research was conducted ethically in accordance with the World Medical Association of Helsinki and was approved by the Ethics Committee at the University of Gothenburg (788-18). The subjects received both oral and written information about the study and gave their informed consent prior to the start of the study.

Consent for publication

Not applicable (the manuscript does not include details, images, or videos relating to an individual person).

\section{Competing interests}

The authors declare no potential conflict of interest with respect to the authorship and/or publication of this article.

\section{Author details}

${ }^{1}$ Department of Cariology, Institute of Odontology, The Sahlgrenska Academy, University of Gothenburg, Gothenburg, Sweden. ${ }^{2}$ Department of Pediatric Dentistry and Orthodontics, College of Dentistry, Taibah University, Medina, Saudi Arabia. ${ }^{3}$ Specialist Clinic of Orthodontics, Public Dental Service, Region Västra Götaland, Gothenburg, Sweden. ${ }^{4}$ Department of Orthodontics, Institute of Odontology, The Sahlgrenska Academy, University of Gothenburg, Gothenburg, Sweden. ${ }^{5}$ Department of Pediatric Dentistry and Orthodontics, College of Dentistry, King Saud University, Riyadh, Saudi Arabia. 
Received: 25 May 2021 Accepted: 31 August 2021

Published online: 06 October 2021

\section{References}

1. Selwitz RH, Ismail Al, Pitts NB. Dental caries. Lancet. 2007;369:51-9.

2. Fejerskoy O, Kidd, E. Dental Caries. 2nd ed. Wiley-Blackwell.2003:29-48.

3. Opal S, Garg S, Jain J, Walia I. Genetic factors affecting dental caries risk. Aust Dent J. 2015;60(1):2-11.

4. Chapple ILC, Bouchard P, Cagetti MG, Campus G, Carra MC, Cocco F Interaction of lifestyle, behaviour or systemic diseases with dental caries and periodontal diseases: consensus report of group 2 of the joint EFP/ORCA workshop on the boundaries between caries and periodontal diseases. J Clin Periodontol. 2017:18:39-51.

5. Eckert R, He J, Yarbrough DK, Qi F, Anderson MH, Shi W. Targeted killing of Streptococcus mutans by a pheromone-guided "smart" antimicrobial peptide. mBio. 2006;50:3651-7.

6. Ganzle M, Holtzel A, Walter J, Jung G, Hammes W. Characterization of reutericyclin produced by Lactobacillus reuteriLTH2584. Appl Environ Microbiol. 2000;66:4325-33.

7. Lewis SJ, Freedman AR. Review article: the use of biotherapeutic agents in the prevention and treatment of gastrointestinal disease. Aliment Pharmacol Ther. 1998:12:807-22.

8. Isolauri E, Sütas $Y$, Kankaanpää P, Arvilommi H, Salminen S. Probiotics: effects on immunity. Am J Clin Nutr. 2001;73:444-50.

9. Çaglar E, Sandalli N, Twetman S, Kavaloglu S, Ergeneli S, Selvi S. Effect of yogurt with Bifidobacterium DN-173 010 on salivary mutans streptococci and lactobacilli in young adults. Acta Odontol Scand. 2005;63:317-20.

10. Cildir SK, Germec D, Sandalli N, Ozdemir Fl, Arun T, Twetman S. Reduction of salivary mutans streptococci in orthodontic patients during daily consumption of yoghurt containing probiotic bacteria. Eur J Orthod. 2009; 31:407-11.

11. Näse L, Hatakka K, Savilahti E, Saxelin M, Pönkä A, Poussa T. Effect of longterm consumption of a probiotic bacterium, lactobacillus rhamnosus GG, in milk on dental caries and caries risk in children. Caries Res. 2001;35:412-20.

12. Petersson LG, Magnusson K, Hakestam U, Baigi A, Twetman S. Reversal of primary root caries lesions after daily intake of milk supplemented with fluoride and probiotic lactobacilli in older adults. Acta Odontol Scand. 2011; 69:321-7.

13. Jing D, Hao J, Shen Y, Tang G, Lei L, Zhao Z. Effect of fixed orthodontic treatment on oral microbiota and salivary proteins. Exp Ther Med. 2019;5: 4237-43.

14. Alforaidi SA, Bresin A, Almosa N, Lehrkinder A, Lingström P. Oral colonisation after the administration of drops containing lactobacillus reuteri. Oral Health Prev Dent. 2020;1:1017-23.

15. Carlén A, Hassan H, Lingström P. The, "strip method": a simple method for plaque pH assessment. Caries Res. 2010;44:341-4.

16. Bardow A., Vissink A. Saliva and caries development. In O. Fejerskov, B Nyvad and E Kidd, editors. Dental caries: The disease and its clinical management. Oxford: Wiley Blackwell, Third edition. 2015;83-106.

17. Ericsson $Y$. Clinical investigations of the salivary buffering action. Acta Odontol Scand. 1959;17:131-65.

18. Choi EJ, Lee SH, Kim YJ. Quantitative real-time polymerase chain reaction for Streptococcus mutans and Streptococcus sobrinus in dental plaque samples and its association with early childhood caries. Int J Paediatr Dent. 2009;2:141-7.

19. Byun R, Nadkarni MA, Chhour KL, Martin FE, Jacques NA, Hunter N. Quantitative analysis of diverse lactobacillus species present in advanced dental caries. J Clin Microbiol. 2004;7:3128-36.

20. Vestman NR, Hasslöf P, Keller MK, Granström E, Roos S, Twetman S, et al. Lactobacillus reuteri influences regrowth of mutans streptococci after fullmouth disinfection: a double blind, randomised controlled trial. Caries Res. 2013;4:338-45.

21. Täpp J, Thollesson M, Herrmann B. Phylogenetic relationships and genotyping of the genus streptococcus by sequence determination of the RNase P RNA gene, rnpB. Int J Syst Evol. 2003:53:1861-71.

22. Gizani S, Petsi G, Twetman S, Caroni C, Makou M, Papagianoulis L. Effect of the probiotic bacterium lactobacillus reuteri on white spot lesion development in orthodontic patients. Eur J Orthod. 2016:38:85-9.

23. Pinto GS, Cenci MS, Azevedo MS, Epifanio M, Jones MH. Effect of yogurt containing Bifidobacterium animalis subsp. lactis DN-173010 probiotic on dental plaque and saliva in orthodontic patients. Caries Res. 2014;48:63-8.
24. Jose JE, Padmanabhan S, Chitharanjan AB. Systemic consumption of probiotic curd and use of probiotic toothpaste to reduce Streptococcus mutans in plaque around orthodontic brackets. Am J Orthod Dentofac Orthop. 2013:144:67-72.

25. Campus G, Cocco F, Carta G, Cagetti MG, Simark C, Strohmenger L. Effect of a daily dose of lactobacillus brevis CD2 lozenges in high caries risk schoolchildren. Clin Oral Investig. 2014;18:555-61.

26. Keller MK, Hasslöf P, Dahlén G, Stecksén-Blicks C, Twetman S. Probiotic supplements (lactobacillus reuteri DSM 17938 and ATCC PTA 5289) do not affect regrowth of mutans streptococci after full-mouth disinfection with chlorhexidine: a randomized controlled multicenter trial. Caries Res. 2012;46: 140-6.

27. Meurman JH, Stamatova I. Probiotics: contributions to oral health. Oral Dis. 2007;13:443-51.

28. Stephan RM. Changes in hydrogen-ion concentration on tooth surfaces and in carious lesions. J Am Dent Assoc. 1940;27:718-23.

29. Belli WA, Marquis RE. Adaptation of streptococcus mutans and enterococcus hirae to acid stress in continuous culture. Appl Environ Microbiol. 1991;57: 1134-8.

30. Corbett JA, Brown LR, Keene HJ, Horton IM. Comparison of streptococcus mutans concentrations in non-banded and banded orthodontic patients. J Dent Res. 1981;60:1936-42.

31. Zachrisson BU. Oral hygiene for orthodontic patients: current concepts and practical advice. Am J Orthod Dentofac Orthop. 1974;66:487-97.

32. Haukioja A. Probiotics and oral health. Eur J Dent. 2010;4:348-55.

33. Forsberg CM, Brattström V, Malmberg E, Nord CE. Ligature wires and elastomeric rings: two methods of ligation, and their association with microbial colonization of Streptococcus mutans and lactobacilli. Eur J Orthod. 1991;13:416-20.

34. Corless CE, Guiver M, Borrow R, Edwards V, Kaczmarski EB, Fox AJ. Contamination and sensitivity issues with a real-time universal 165 rRNA PCR. J Clin Microbiol. 2000;38:1747-52.

35. Gorelick L, Geiger AM. Incidence of white spot formation after bonding and banding. Am J Orthod Dentofac Orthop. 1982;2:93-8.

36. Artun J, Brobakken BO. Prevalence of carious white spots after orthodontic treatment with multibonded appliances. Eur J Orthod. 1986;8:229-34.

37. Chapman JA, Roberts WE, Eckert GJ, Kula KS, González C. Risk factors for incidence and severity of white spot lesions during treatment with fixed orthodontic appliances. Am J Orthod Dentofac Orthop. 2010;138:188-94.

\section{Publisher's Note}

Springer Nature remains neutral with regard to jurisdictional claims in published maps and institutional affiliations.

Ready to submit your research? Choose BMC and benefit from:

- fast, convenient online submission

- thorough peer review by experienced researchers in your field

- rapid publication on acceptance

- support for research data, including large and complex data types

- gold Open Access which fosters wider collaboration and increased citations

- maximum visibility for your research: over $100 \mathrm{M}$ website views per year

At $\mathrm{BMC}$, research is always in progress.

Learn more biomedcentral.com/submissions 